\title{
Computation of primary production from remote sensing of ocean colour at the northwestern Atlantic C-SOLAS Lagrangian site
}

\author{
M. H. Forget ${ }^{1, *}$, C. Fuentes-Yaco ${ }^{2}$, S. Sathyendranath ${ }^{3}$, T. Platt ${ }^{4}$, \\ J. Pommier ${ }^{5}$, E. Devred ${ }^{2}$ \\ ${ }^{1}$ Department of Biology, Dalhousie University, 1355 Oxford Street, Halifax, Nova Scotia B3H 4J1, Canada \\ ${ }^{2}$ Department of Oceanography, Dalhousie University, 1355 Oxford Street, Halifax, Nova Scotia B3H 4J1, Canada \\ ${ }^{3}$ Plymouth Marine Laboratory, Prospect Place, The Hoe, Plymouth, Devon PL1 3DH, UK \\ ${ }^{4}$ Ocean Science Division, Bedford Institute of Oceanography, 1 Challenger Drive, Dartmouth, Nova Scotia B2Y 4A2, Canada \\ ${ }^{5}$ Université du Québec à Rimouski, 300 allée des Ursulines, Rimouski, Québec G5L 3A1, Canada
}

\begin{abstract}
At the C-SOLAS Lagrangian Study site, the phytoplankton community was dominated by diatoms in declining bloom conditions, which were characterised by a decrease in primary production over time. Measurements of primary production were performed using photosynthesis-light experiments and simulated in situ incubations. Several methods were used to assign photosynthetic parameters for estimation of primary production from remote-sensing of ocean colour: (1) the nearestneighbour method (NNM), (2) a temperature-dependent model, (3) an iterative approach to retrieve photosynthetic parameters from in situ measurements of phytoplankton production, and (4) average values of measured parameters. Owing to the declining status of the diatom population and its patchy distribution, the magnitude of primary production measured from in situ incubations was highly variable. Under bloom conditions, all methods underestimated production compared with results of simulated in situ measurements; however, the NNM provided the closest estimates to the in situ measurements. In the declining bloom phase, the NNM overestimated primary production, whereas the iterative method returned estimates of production in good agreement with the in situ observations. In conditions characterized by mixed-phytoplankton populations, the NNM returned estimates in agreement with the observations. A new method is proposed for classifying image pixels using criteria accessible to remote sensing, according to the phase of the diatom bloom (bloom versus declining conditions) and according to community composition (diatom versus mixed population). Upon separating the database used for parameter assignment into 2 parts, one representing the general phytoplankton community and the other representing declining diatom conditions, estimates of chlorophyll a-normalised water-column production were in good agreement with in situ observations.
\end{abstract}

KEY WORDS: Response - Primary production - Remote sensing of ocean colour - Photosynthetic parameters

\section{INTRODUCTION}

Interaction between the surface layer of the ocean and the atmosphere is at the centre of the SOLAS programme and its Canadian component, C-SOLAS. The main goal is to understand and quantify at the global scale the exchange of gases that affect processes in the atmosphere, e.g. DMS (dimethylsulphide), which triggers the formation of clouds (see review by Malin et al. 1992), $\mathrm{O}_{2}$, which is essential for heterotrophic organisms, and $\mathrm{CO}_{2}$, which is a major contributor to the enhanced greenhouse effect. Carbon assimilated 
through phytoplankton photosynthesis in the ocean

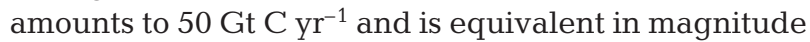
to terrestrial primary production (Longhurst et al. 1995, Behrenfeld \& Falkowski 1997, Behrenfeld et al. 2001). Moreover, through the biological pump, a proportion of this carbon will be transferred to the ocean floor via sedimentation of organic material (Longhurst \& Harrison 1989). Quantification of primary production in the ocean is therefore of central importance to programmes such as SOLAS.

Remote sensing of ocean colour is an effective method for computing primary production on a global scale (Longhurst et al. 1995, Antoine et al. 1996, Behrenfeld \& Falkowski 1997). The method relies on estimation of chl $a$ at the surface, estimation of the attenuation coefficient for downwelling light and the assignment of parameters describing the biomass profile at each image pixel, as well as the photosynthetic response to available light (Platt \& Sathyendranath 1988, Sathyendranath \& Platt 1993). The first 2 estimations can be obtained directly from oceancolour algorithms (see Sathyendranath \& Platt 1993), whereas parameter assignment relies largely on indirect approaches. Biomass profiles have been related to chlorophyll concentration at the surface (Morel \& Berthon 1989). However, a global application of such a relationship remains questionable (Longhurst et al. 1995). There is no significant relationship between either of the photosynthetic parameters and chl a concentration (Platt et al. 2005). Thus, using ocean-colour as a direct tool to assign photosynthetic parameters is not a robust option. The use of temperature as a proxy to assign photosynthetic parameters (Antoine et al. 1996, Behrenfeld \& Falkowski 1997) is attractive because sea-surface temperature can be retrieved from remote sensing in the far infra-red wavelengths. However, changes in phytoplankton community composition and the increase in nutrient concentration that often accompanies a decrease in temperature may lead to trends that are not predictable from laboratory experiments (Eppley 1972).

To assign photosynthetic parameters, some authors have proposed using archived data, either regrouping the parameters in space and time according to specific biogeochemical provinces (Longhurst et al. 1995, Sathyendranath et al. 1995), or alternatively arranging them according to temperature, chlorophyll and sampling season as a tool for recovering parameters on a pixel-by-pixel basis using remotely-sensed temperature and chlorophyll as inputs (the nearest-neighbour method [NNM]; Platt \& Sathyendranath 2002, Platt et al. in press). Others have preferred use of environmental proxies such as temperature (Antoine et al. 1996, Behrenfeld \& Falkowski 1997). Important limitations exist for each of these methods. Archived data on pho- tosynthetic capacity are scarce, and particularly so in the southern hemisphere. However, in regions where the data are abundant, the assignment of photosynthetic parameters using the nearest-neighbour method (NNM) provides good estimates of primary production (Platt et al. in press). Thus, expanding the archived database on parameters by deriving them from in situ production could increase its general applicability (Forget et al. 2007).

Here, for the C-SOLAS spring cruise in the North West Atlantic we compare photosynthetic parameters and water-column production estimated using different approaches to assign parameters. The photosynthetic parameters obtained were used to establish a map of primary production for the C-SOLAS Lagrangian site (Northwest Atlantic shelf) during the spring bloom of 2003, for which measurements of in situ production are available for comparison.

\section{ASSIGNMENT OF PARAMETERS}

Profile parameter. Biomass profiles can be parameterised using a shifted Gaussian function where 4 parameters are required: $B_{0}$ the background biomass, $z_{m}$ the depth of the biomass peak maximum, $\sigma$ which defines the width of the peak, and $h$ the integral under the Gaussian curve (Platt et al. 1988). Two additional parameters are also derived from the above set: $H$, the height of the biomass peak at depth $z_{m}$ where $H=h / \sigma \sqrt{2 \pi}$ and $\rho$ that describes the shape of the profile $\left[\rho=H /\left(H+B_{0}\right)\right]$. In a remote-sensing context, only 3 parameters are needed from the archive $\left(z_{m}, \sigma\right.$ and $\rho$ ) since information on surface and near surface biomass is available from ocean-colour data. In the following computations, we have assumed $B$ at the surface, computed from the profile parameters, to be equal to satellite-derived chlorophyll concentration.

Photosynthetic parameters. The 2 photosynthetic parameters used for calculation of primary production are derived by fitting data from photosynthesisirradiance $(P-E)$ experiments to the equation of Platt et al. (1980):

$$
P^{B}=P_{m}^{B}\left[1-\exp \left(-E \alpha^{B} / P_{m}^{B}\right)\right]
$$

where biomass-normalised production $P^{B}$ is a function of the initial slope $\alpha^{B}$ (measured in light-limited conditions) and the assimilation number $P_{m}^{B}$ (the plateau reached under light-saturating conditions of irradiance $E$ ).

Four methods of parameter assignment were compared in this study, as follows.

Nearest-neighbour method. The NNM assigns parameters by taking the values of chlorophyll and 
temperature at the desired pixel and, with these values, searching a database in which photosynthetic parameters are archived as a function of chlorophyll and temperature. Subsequently, the required parameters of 10 nearest neighbours (in a Euclidian sense) of the archive points are extracted and averaged after weighting the archive values according to their separation in time from the day number of the satellite image (Platt et al. in press). In this study, we used a substantial database of photosynthetic parameters for the Northwest Atlantic (about 1500 entries compiled over 3 decades) from which the parameters corresponding to the Lagrangian study were excluded.

Temperature-dependent model. A relationship between surface $(0$ to $20 \mathrm{~m})$ values of $\alpha^{B}$ (mg C mg chl $a^{-1}\left[\mathrm{~W} \mathrm{~m}^{-2}\right]^{-1} \mathrm{~h}^{-1}$ ) and corresponding temperature $\left({ }^{\circ} \mathrm{C}\right)$ was established by Platt et al. (2005) for data from 16 cruises on the Scotian Shelf and Labrador sea from 1997 to 2003. The fit (not provided by Platt et al. 2005) is significant and follows the relationship shown in Fig. 1a. Similarly, Bouman et al. (2005) found that $P_{m}^{B}$ (mg C mg chl $a^{-1} \mathrm{~h}^{-1}$ ) could be predicted well for the North West Atlantic region using the relationship in Fig. $1 \mathrm{~b}$.

The iterative procedure. The iterative procedure for retrieval of photosynthetic parameters from in situ production was proposed initially by Platt \& Sathyendranath (1993) and developed and implemented by Forget et al. (2007) who provided a thorough description of the model. Briefly, the iteration is applied to 2 sets of linear regressions: (1) between the watercolumn primary production normalised to the watercolumn chl $a(\Lambda)$ and the total irradiance at the surface $\left(E_{T}\right)$, and (2) between a function $f$ of $E_{*}^{m}$, the (noon) maximum irradiance at the surface normalised to $E_{k}\left(=P_{m}^{B} / \alpha^{B}\right)$, the photo-acclimation parameter, and $E_{*}^{m}$ itself. The procedure is applied in 2 parts: the initial slope $\alpha^{B}$ is estimated from a linear regression (forced through the origin) using points with daily irradiances $<15 \mathrm{~mol}$ photons $\mathrm{m}^{-2} \mathrm{~d}^{-1}$ and the assimilation number $P_{m}^{B}$ is estimated using points with daily irradiance $>50$ mol photons $\mathrm{m}^{-2} \mathrm{~d}^{-1}$ (Forget et al. 2007). When the observed irradiance range did not offer any points in either of the categories, the 2 points from the lowest and highest irradiance levels, respectively, were used for the estimation. The regressions are carried out first with an initial guess for $E_{k}$ i the estimated parameter values are then used to recalculate $E_{k}$, and the iteration is repeated until convergence of the photosynthetic parameters.

Average of measured parameter. In this method, the average parameters from the study area were assigned to all the pixels in the satellite image of the study area for which production was computed.
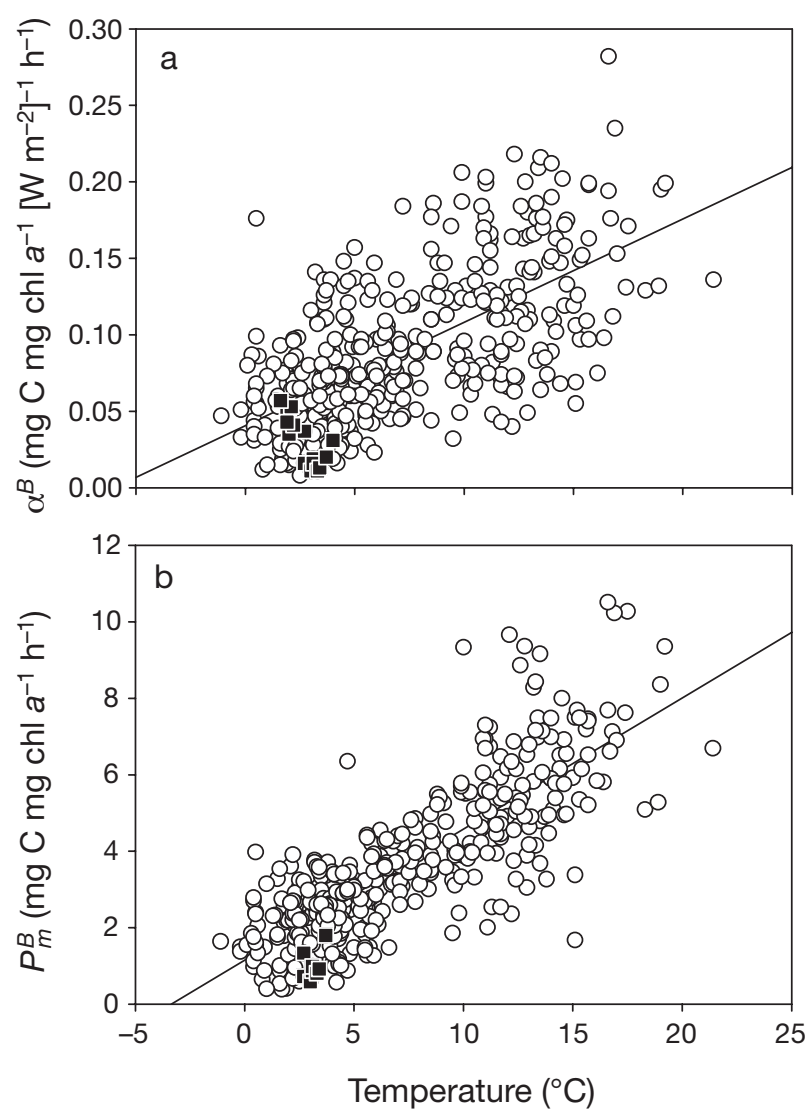

Fig. 1. The relationship between surface (0 to $20 \mathrm{~m})$ values of photosynthetic parameters $\left(\alpha^{B}\right.$ in $\mathrm{mg} C \mathrm{mg} \operatorname{chl~} a^{-1}\left(\mathrm{~W} \mathrm{~m}^{-2}\right)^{-1}$ $\mathrm{h}^{-1}$ and $P_{m}^{B}$ in mg C mg chl $a^{-1} \mathrm{~h}^{-1}$ ) and corresponding temperature $\left({ }^{\circ} \mathrm{C}\right)$ for 16 cruises on the Scotian Shelf and Labrador Sea from 1997 to 2003 (O) (Platt et al. 2005, Bouman et al. 2005). (a) The fit between $\alpha^{B}$ and temperature (not provided by Platt et al. 2005) is significant and follows the relationship $\alpha^{B}=0.006 T+0.041, \mathrm{r}^{2}=0.41, \mathrm{n}=416$. (b) The fit between $P_{m}^{B}$ and temperature follows the relationship $P_{m}^{B}=0.034 T+1.15$, $\mathrm{r}^{2}=0.66, \mathrm{n}=416$ (Bouman et al. 2005). The values measured during the Lagrangian study ( $\mathbf{\square})$ are superimposed on the above-mentioned relationships

\section{MATERIALS AND METHODS}

Study sites. The C-SOLAS Lagrangian study took place during spring 2003 (April 25 to May 02: Days D1 to D8) on the Northwest Atlantic shelf between $43^{\circ} \mathrm{N}$ and $44^{\circ} \mathrm{N}$, and $57^{\circ} \mathrm{W}$ and $58.5^{\circ} \mathrm{W}$ (Fig. 2). The same site was sampled again after $2 \mathrm{wk}$ (D20). A mooring followed the water mass from D1 to D7, and the phytoplankton in the water mass was dominated by a diatom community in decline (Pommier et al. 2008). Contact with the water mass was lost on D8 when the cable connecting the mooring to the underwater sail was accidentally detached.

Primary production measurements. Photosynthesis was measured using 2 different techniques. The first 


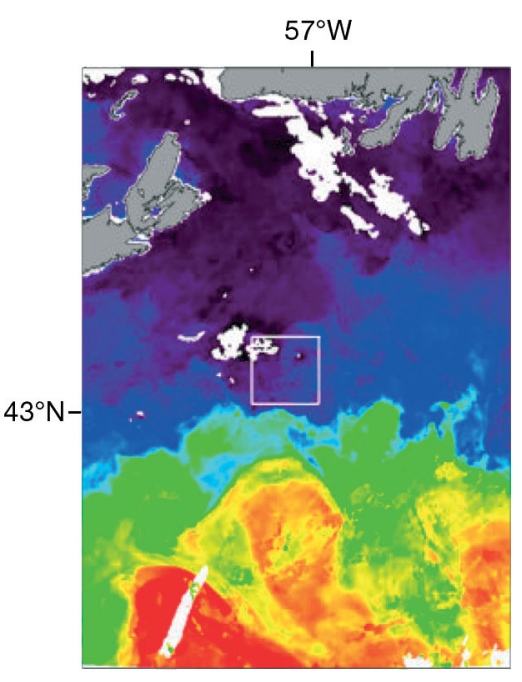

a Sea surface temperature

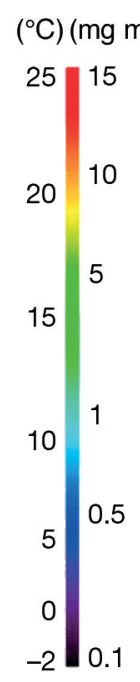

Fig.

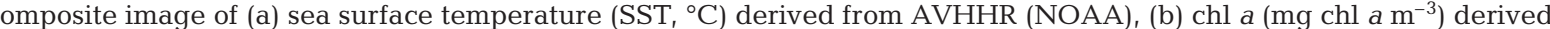
from visible spectral radiometry (ocean colour), SeaWiFS, and (c) percentage of diatom-dominated pixels during the period of study (Sathyendranath et al. 2004). Images span the time period from April 24-May 2, 2003. The upper left corner of each image is at $48^{\circ} \mathrm{N}$ and $62^{\circ} \mathrm{W}$, the lower right is at $39^{\circ} \mathrm{N}$ and $53^{\circ} \mathrm{W}$. The Lagrangian site is enclosed by the white box: lower right corner $43^{\circ} \mathrm{N}, 57^{\circ} \mathrm{W}$ and upper left corner $44^{\circ} \mathrm{N}, 58.5^{\circ} \mathrm{W}$ technique, the $P-E$ experiment, required incubation of samples in a light-gradient incubator; carbon assimilation was estimated using ${ }^{14} \mathrm{C}$ uptake (Irwin et al. 1990). The photosynthetic parameters were obtained by fitting equation (1) to the observations.

Simulated in situ primary production was measured using a ${ }^{14} \mathrm{C}$ technique described by Pommier et al. (2008). Briefly, the bottles were incubated for 8 to $10 \mathrm{~h}$ on deck in temperature-controlled chambers, shaded to mimic the different optical depths. Water-column production was then computed from the production $P_{i}$ in each of the $n$ layers, as:

$$
\int P(z) \mathrm{d} z=\sum_{i=1}^{n} P_{i} L_{i}
$$

where $L_{i}$ is the thickness of the $i^{\text {th }}$ layer.

Computation of primary production. Primary production was calculated at the C-SOLAS site using a spectral, non-uniform model (Sathyendranath et al. 1989). We used the Ocean Primary Production software (available from IOCCG: www.ioccg.org) with numerical integration forced by Bird's (1984) clear-sky spectral irradiance model to estimate light at the sea surface; the ratio of yellow-substance absorption at $440 \mathrm{~nm}$ was set to $30 \%$ of the phytoplankton absorption at that wavelength (Sathyendranath et al. 2001).

Satellite application. Chl a concentration was estimated from SeaWiFS images using the NASA OC4 version 4.3 algorithm. We produced a composite image for the last 2 wk of April 2003. The photosynthetic parame- ters were assigned using 4 different approaches: (1) spatially homogeneous, using the average of measured photosynthetic parameters, (2) spatially homogeneous, using the pair of parameters retrieved from the iteration approach, (3) spatially heterogeneous, using the NNM and (4) spatially heterogeneous using the temperature model. Results from the different approaches were compared with independent in situ observations from the C-SOLAS Lagrangian study.

\section{RESULTS}

\section{C-SOLAS Lagrangian site}

Composite images representing spatial features of SST, chl $a$ and fields of diatom distribution during the Lagrangian study are shown in Fig. 2. The oceanographic features indicate that the Lagrangian study location was in the North Western Coastal Shelf (NWCS) province (Longhurst 1998). The images show warmer waters (Fig. 2a) with low phytoplankton pigment concentrations (Fig. 2b) south of the Lagrangian study area, corresponding to the Gulf Stream. Northern regions of NWCS were characterised by cooler and biologically richer waters. Cold water $\left(\sim 0^{\circ} \mathrm{C}\right)$ and high pigment concentration ( $>10 \mathrm{mg} \mathrm{m}^{-3}$ ) were found north of $43^{\circ} \mathrm{N}$, related to the southern Gulf of St. Lawrence, the Grand Banks of Newfoundland and the northeastern Scotian Shelf. The diatom population was not 
homogeneously distributed over the Lagrangian study site; there were high occurrences in the northwestern corner and the eastern portion (Fig. 2c). As shown from the time-series of satellite images, field measurements covered only the decline of the spring bloom; the peak occurred in the previous week (Fig. 3).

The Lagrangian time series shows a decline in chl a concentration from D1 to D8 (Fig. 4a). Production was fairly high at D1 and D2, but decreased by D3, staying stable for the remainder of the sampling period (Fig. 4b). Water-column production values normalised to photic-zone chlorophyll $(\Lambda)$ were similar on D1 and D2 to those on D8 and D20. However, D3 to D7 estimates were significantly lower $(t$-test, $\mathrm{p}<0.01)$. Based on the magnitude of $\Lambda, 3$ classes were identified (Fig. 4b). We know from microscope taxonomic counts that Class I was composed of diatom bloom samples, Class II of declining diatom samples and Class III of mixed community samples (Pommier et al. 2008). Pigment analyses matched the findings from microscope taxonomic analyses (except for D8), with a ratio of fucoxanthin to chl $a>0.4\left(\mathrm{w} \mathrm{w}^{-1}\right)$ from D1 to D8 and a decrease on D20 (Fig. 4c). A ratio of fucoxanthin to chl $a>0.4$ indicates samples dominated by diatoms (Sathyendranath et al. 2004). Also, the increase of chlorophyll-specific absorption by phytoplankton over the time period is an index of the cell size decrease in the phytoplankton community (Fig. 4c).

The photosynthetic parameters (Fig. 4d) of Classes I and III had higher average values (mean \pm SD [units:

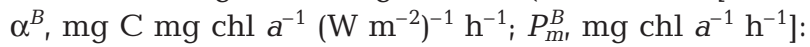
Class I: $\alpha^{B}=0.024 \pm 0.04 ; P_{m}^{B}=1.04 \pm 0.43$; Class III: $\alpha^{B}=$ $\left.0.024 \pm 0.0057 ; P_{m}^{B}=1.92 \pm 0.17\right)$ than Class II $\left(\alpha^{B}=\right.$ $\left.0.014 \pm 0.0035 ; P_{m}^{B}=0.84 \pm 0.15\right)$. Platt et al. (1992)

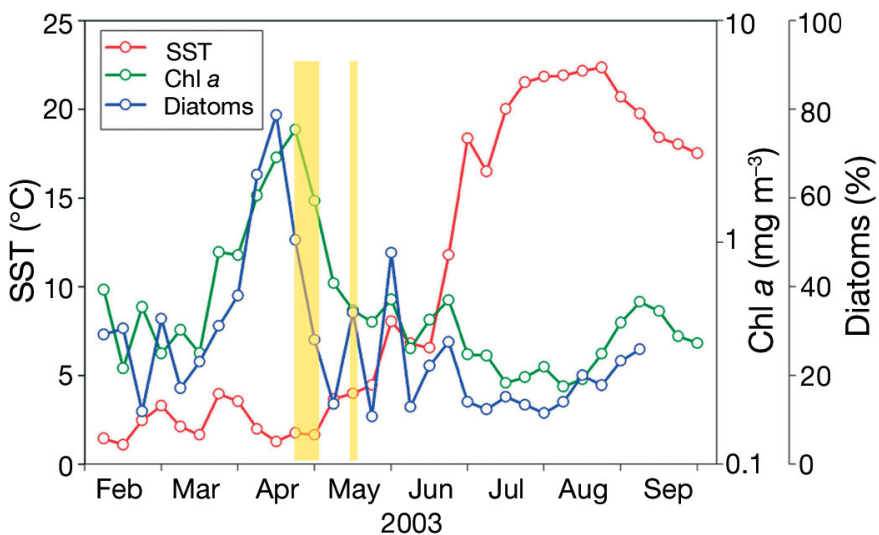

Fig. 3. Average weekly values of satellite-derived sea surface temperature $\left(\mathrm{SST},{ }^{\circ} \mathrm{C}\right)$, chl a $\left(\mathrm{mg} \mathrm{m}^{-3}\right)$ and percentage occurrence of diatom-dominated pixels between February and September, 2003 in the Lagrangian study area. The yellow bars indicate periods of in situ measurements: April 24 to May 2 (D1-D8) and May 13 to 15 (D19-D21) reported a steady decrease in photosynthetic parameters in the declining phase of a spring bloom in the Sargasso Sea, consistent with the findings in our study. A positive correlation was found between $\Lambda$ and $P_{m}^{B}$ (Pearson's $\mathrm{r}=0.89$ ), with D2 as a probable outlier. However, no significant correlations were found between $\Lambda$ and $\alpha^{B}$, either from surface samples or from the deeper layers ( $p>0.05$, both depths). The iterative approach was applied only to Class II samples (declining bloom phase) because this was the only phase for which a sufficient number of samples was available. There were only 2 data points each for Classes I and III; these were excluded from the iterative approach.

\section{Assignment of photosynthetic parameters}

Photosynthetic parameters were assigned to the 9 stations (D1-D8 and D20) using 3 different approa-
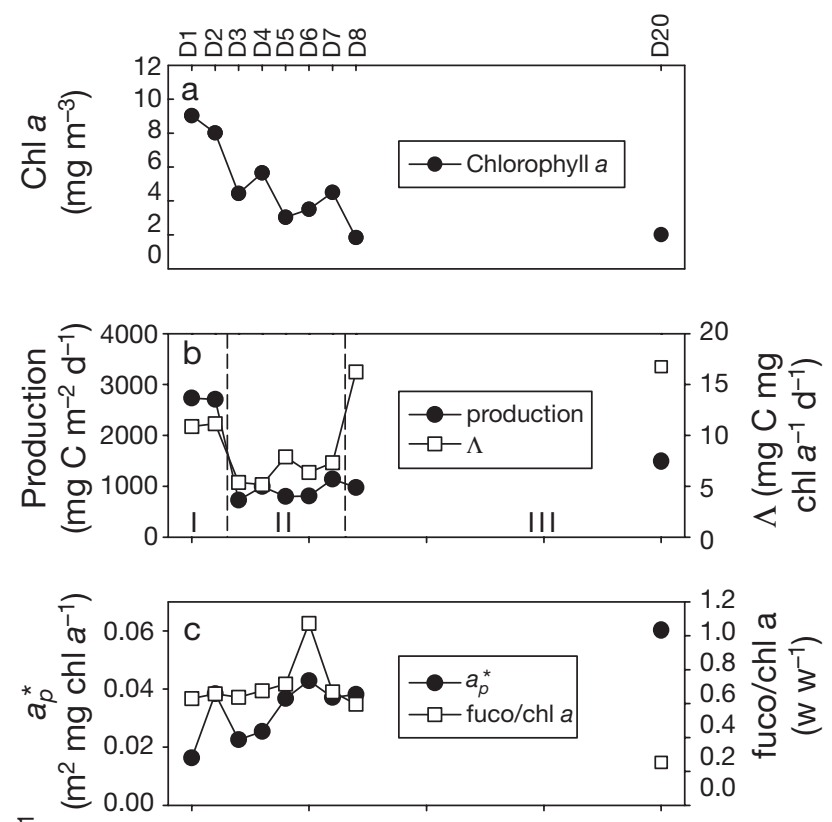

$$
\top^{\top}
$$
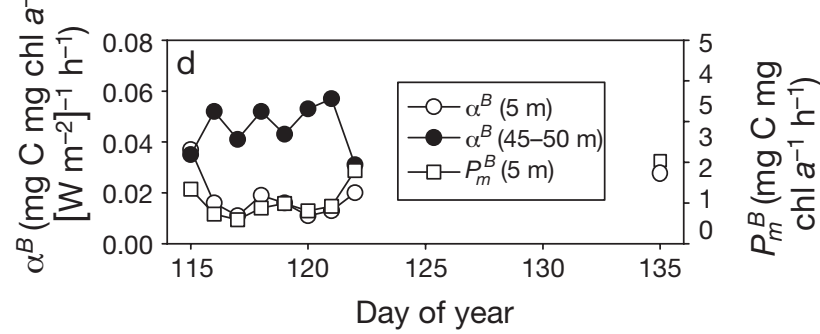

Fig. 4. Northwest Atlantic Shelf time-series April 24, 2003May 14, 2003. (a) average chl a concentration over the photic

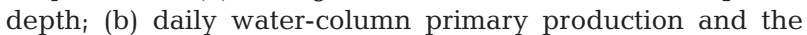
same normalised to the photic-zone chlorophyll biomass, $\Lambda$ (time series is divided into 3 classes [I, II, III] according to $\Lambda$ as described in Forget et al. 2007); (c) phytoplankton specific absorption at $440 \mathrm{~nm}\left(a_{p}^{*}\right)$ and fucoxanthin/chl a ratio; (d) photosynthetic parameters $\alpha^{B}$ and $P_{m}^{B}$ 
ches: the NNM, the temperature-dependent model and the iterative approach. The mean values of parameters obtained using each method of assignment were compared with the means of the measured parameters (Table 1). In a previous study (Platt et al. in press) that dealt with estimation of parameters in spring 2004, good agreement was found between estimates of photosynthetic parameters using the NNM and measured parameters (Table 1). However, in the present study, the NNM overestimated both parameters whereas the temperature model provided mean values much closer to the means of the measured parameters. The iterative approach significantly underestimated $\alpha^{B}$ (although the estimate falls within the range of measurements) whereas estimated $P_{m}^{B}$ values agreed well with the means of measured values.

Water-column primary production was computed for the 9 stations using the 3 different approaches for assignment of photosynthetic parameters combined with the measured chl a profile parameters (Table 2). These estimates were compared with water-column production measured from simulated in situ incuba- tions and with production calculated using the measured photosynthetic parameters. Owing to high variability in the magnitude of the in situ production, the comparison was extended on a class-by-class basis representing the different phases of the diatom bloom (Class I is the bloom phase and Class II is the declining phase) and the mixed community (Class III). In Class I, the magnitude of the production measured in situ was much higher than the mean production calculated using the photosynthetic parameters. It seems that even the measured parameters did not capture the increased productivity of the bloom event. Of all the methods used to compute production, only the NNM returned values that were not significantly different from the measured production. In Class II, the declining-diatom phase, the NNM overestimated water-column production, whereas all the other approaches compared well with the measured production. In Class III, although production estimated from all the methods was not significantly different from the in situ measurements, the NNM provided estimates of water-column production that were closest.

Table 1. Photosynthetic parameters $\alpha^{B}\left(\mathrm{mg} \mathrm{C} \mathrm{mg} \mathrm{chl} a^{-1}\left[\mathrm{~W} \mathrm{~m}^{-2}\right]^{-1} \mathrm{~h}^{-1}\right)$ and $P_{m}^{B}\left(\mathrm{mg} \mathrm{C} \mathrm{mg} \mathrm{chl} a^{-1} \mathrm{~h}^{-1}\right)$ estimated for the Scotian Shelf (spring 2004) using the nearest-neighbour method (NNM) and compared with measured values (Platt et al. in press) and for the Lagrangian site on the Scotian Shelf (spring 2003) comparing 3 different approaches of parameter assignment with measured values. p: confidence values (p-values) associated with paired $t$-tests between the assigned parameters and the parameters measured using $P-E$ experiments. Data are mean $( \pm \mathrm{SD}$, where indicated). * Significantly different from the parameter measured; ns: not significant

\begin{tabular}{|c|c|c|c|c|c|c|c|c|}
\hline Cruise & $\begin{array}{c}P-E \\
\text { parameters }\end{array}$ & $\begin{array}{c}P-E \\
\text { experiments }\end{array}$ & NNM & $\mathrm{p}$ & $\begin{array}{c}\text { Temperature } \\
\text { model }\end{array}$ & $\mathrm{p}$ & $\begin{array}{c}\text { Iteration } \\
\text { from in situ } \\
\text { production }\end{array}$ & $\mathrm{p}$ \\
\hline Spring 2004 & $\begin{array}{l}\alpha^{B} \\
P_{m}^{B}\end{array}$ & $\begin{array}{c}0.087 \pm 0.022 \\
2.67 \pm 0.61\end{array}$ & $\begin{array}{c}0.089 \pm 0.037 \\
2.90 \pm 1.21\end{array}$ & $\begin{array}{l}\text { ns } \\
\text { ns }\end{array}$ & & & & \\
\hline Spring 2003 & $\begin{array}{l}\alpha^{B} \\
P_{m}^{B}\end{array}$ & $\begin{array}{c}0.032 \pm 0.017 \\
1.01 \pm 0.39\end{array}$ & $\begin{array}{c}0.070 \pm 0.011 \\
1.85 \pm 0.26\end{array}$ & $\begin{array}{l}<0.001^{*} \\
0.007^{*}\end{array}$ & $\begin{array}{c}0.053 \pm 0.003 \\
1.22 \pm 0.02\end{array}$ & $\begin{array}{c}<0.001^{*} \\
\mathrm{~ns}\end{array}$ & $\begin{array}{l}0.016 \\
1.12\end{array}$ & $\begin{array}{c}<0.001^{*} \\
\mathrm{~ns}\end{array}$ \\
\hline
\end{tabular}

Table 2. Comparison of water-column primary production $\left(\mathrm{mg} \mathrm{C} \mathrm{m} \mathrm{m}^{-2} \mathrm{~d}^{-1}\right.$ ) computed with a spectral model using different approaches to assign photosynthetic parameters. The measured chlorophyll profile parameters were used for all assignment methods. Data are mean \pm SD. Class I corresponds to a diatom bloom (Days D1 and D2), Class II spans the decline of a diatom bloom (D3-D7), and Class III corresponds to a mixed community (D8 and D20). p: confidence values (p-values) associated with paired $t$-tests between the production computed from assigned parameters and in situ production; ${ }^{*}$ production computed from assigned parameters and in situ production significantly different; ns: not significant. NNM: nearest-neighbour method

\begin{tabular}{|lccccccccc}
\hline & In situ & $\begin{array}{c}P-E \\
\text { experiments }\end{array}$ & $\mathrm{p}$ & NNM & $\mathrm{p}$ & $\begin{array}{c}\text { Temperature } \\
\text { model }\end{array}$ & $\mathrm{p}$ & $\begin{array}{c}\text { Iteration } \\
\text { from in situ } \\
\text { production }\end{array}$ \\
\hline Class I & $2621 \pm 140$ & $824 \pm 253$ & $0.028^{*}$ & $1385 \pm 143$ & $\mathrm{~ns}$ & $1099 \pm 41$ & $0.029^{*}$ & $597 \pm 28$ & $0.025^{*}$ \\
Class II & $548 \pm 167$ & $387 \pm 90$ & $\mathrm{~ns}$ & $894 \pm 176$ & $0.045^{*}$ & $601 \pm 130$ & $\mathrm{~ns}$ & $337 \pm 78$ & $\mathrm{~ns}$ \\
Class III & $819 \pm 282$ & $466 \pm 67$ & $\mathrm{~ns}$ & $712 \pm 44$ & $\mathrm{~ns}$ & $509 \pm 29$ & $\mathrm{~ns}$ & $278 \pm 19$ \\
Average & $1069 \pm 902$ & $502 \pm 217$ & $0.045^{*}$ & $963 \pm 285$ & $\mathrm{~ns}$ & $691 \pm 253$ & $\mathrm{~ns}$ & $381 \pm 137$ & $0.031^{*}$ \\
\hline
\end{tabular}




\section{Satellite application}

Water-column primary production was computed for the Lagrangian study area from ocean-colour data using 4 parameter-assignment methods (Fig. 5). The fourth method uses average values of the measured photosynthetic parameters homogeneously applied over the Lagrangian study area. The 4 methods of parameter-assignment returned similar trends in water-column production over the area, with high production in the northwestern corner and in the center. This consistency between maps reflects the pattern of chl a concentration estimated from remote sensing of ocean colour. However, discrepancies in the magnitude of the estimated production were found between the 4 maps. Production estimated using the mean value of measured parameters (Fig. 5a) or the set of parameters retrieved by iteration from in situ production of Class II (Fig. 5b) gave maximum values of about $800 \mathrm{mg} \mathrm{C} \mathrm{m}{ }^{-2} \mathrm{~d}^{-1}$, whereas the temperature-dependent model returned a maximum of about $1200 \mathrm{mg} \mathrm{C}$ $\mathrm{m}^{-2} \mathrm{~d}^{-1}$ (Fig. 5c); the NNM estimated a maximum of $2000 \mathrm{mg} \mathrm{C} \mathrm{m}^{-2} \mathrm{~d}^{-1}$ (Fig. 5d). When averaged over the entire region (Table 3 ), the water-column production estimated using the NNM returned values closest to the mean value of production measured in situ, whereas all other approaches underestimated production. However, when normalised to the water-column chl $a$, estimated using the OC4 algorithm from ocean colour data composited over a 2 wk period (Table 3 ), the NNM returned a strong overestimation of the daily water-column production normalised to the photic zone chlorophyll $(\Lambda)$ compared to the in situ measurements, whereas the iterative approach underestimated $\Lambda$. The estimates made using measured parameters and the temperature models both agreed well with the in situ measurements. This discrepancy between the estimates of $\Lambda$ from the NNM and the measurements could be due to a difference in the assigned chl a profile, or the higher resolution of the remote-sensing approach, which returned results from about 4500 pixels compared with the 9 experiments of in situ incubation, as discussed by Platt et al. (in press). However, the discrepancy could also be due to the overestimation of the photosynthetic parameters in the declining phase of the diatom bloom (see Tables $1 \& 2$ ).

To test this hypothesis, an intelligent (conditional branching) algorithm was developed and implemented. In this algorithm, pixels were assigned to one of 3 possible classes using a combination of the diatom identification algorithm (Sathyendranath et al. 2004) and the sign of the rate of change in the remotely-

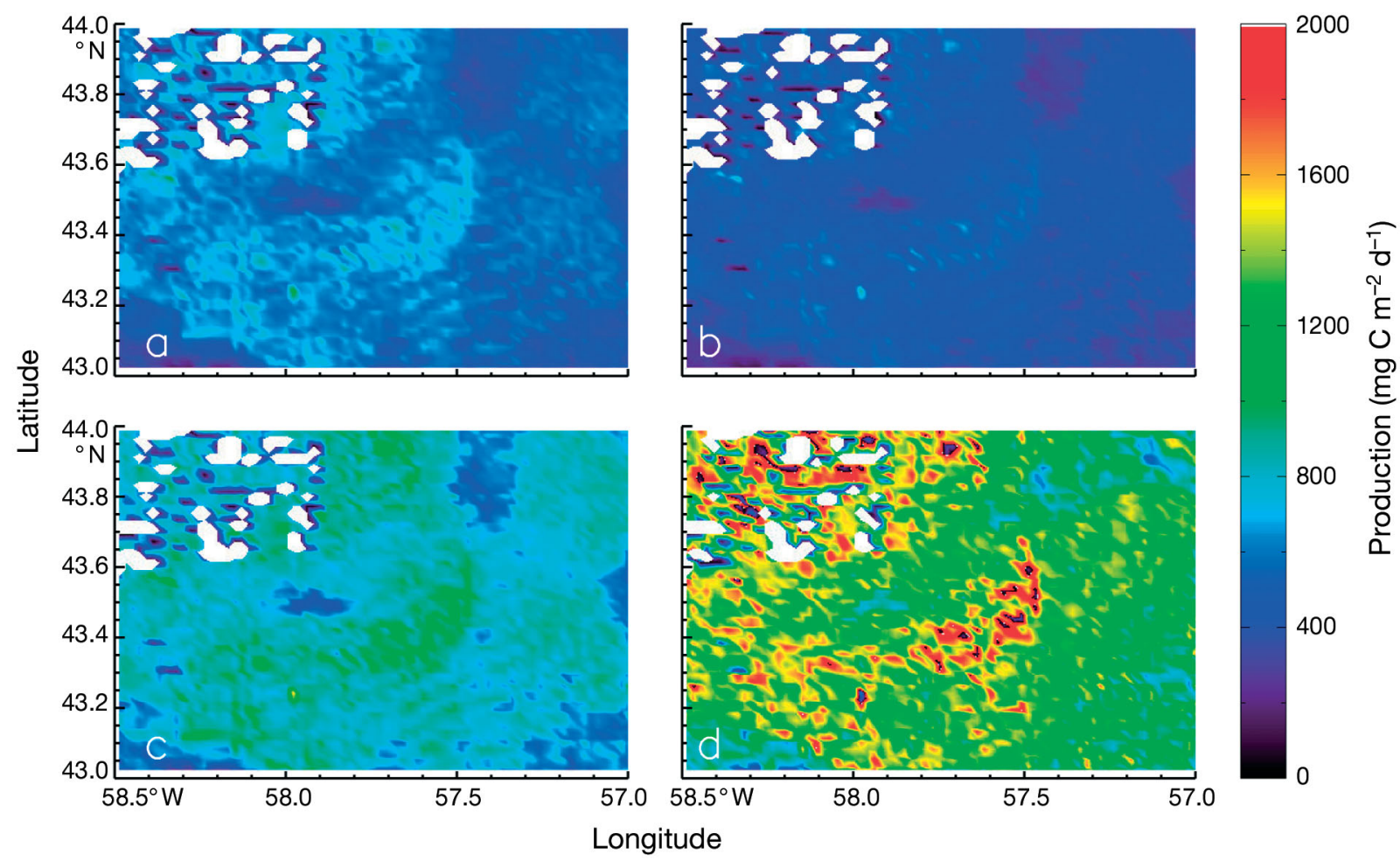

Fig. 5. Water-column primary production $\left(\mathrm{mg} \mathrm{C} \mathrm{m}^{-2} \mathrm{~d}^{-1}\right)$ map from satellite images of ocean colour using 4 different photosynthetic parameter assignment approaches: (a) spatially-homogeneous, using the average of measured photosynthetic parameters; (b) spatially-homogeneous, using the pair of parameters retrieved by the iteration approach; (c) spatially-heterogeneous, using the temperature model; and (d) spatially-heterogeneous, using the NNM 
Table 3. Comparisons between total water-column primary production $\left(\mathrm{mg} \mathrm{C} \mathrm{m}^{-2}\right.$ $\mathrm{d}^{-1}$ ) and water-column primary production normalised to water-column chl a concentration using only the pixels common to all methods of assignment. Data are mean $\pm \mathrm{SD}$. The comparison is made between in situ measurements and corresponding values computed from satellite images of ocean colour using different photosynthetic parameter assignment approaches. Chl a profile parameters were assigned to each pixel using the nearest-neighbour method (NNM) (Platt et al. in press). $t$-tests (for samples with unequal variances) were used to test for significant differences between the production computed from assigned parameters and in situ production; ${ }^{*}$ significant $(\mathrm{p}<0.05)$; ns: not significant

\begin{tabular}{|lcccc|}
\hline $\begin{array}{l}\text { Method of } \\
\text { assignment }\end{array}$ & Production & $\mathrm{p}$ & $P_{Z T} / B_{Z}$ & $\mathrm{p}$ \\
\hline In situ & $1076 \pm 964$ & & $4.58 \pm 2.43$ & \\
$P$ - experiments & $593 \pm 109$ & $\mathrm{~ns}$ & $3.58 \pm 0.72$ & $\mathrm{~ns}$ \\
NNM & $1260 \pm 334$ & $\mathrm{~ns}$ & $7.68 \pm 2.39$ & $0.015^{*}$ \\
Temperature model & $802 \pm 130$ & $\mathrm{~ns}$ & $4.90 \pm 1.24$ & $\mathrm{~ns}$ \\
Iteration from in situ & $454 \pm 84$ & $\mathrm{~ns}$ & $2.74 \pm 0.58$ & $0.032^{*}$ \\
production & $994 \pm 491$ & $\mathrm{~ns}$ & $5.85 \pm 2.82$ & $\mathrm{~ns}$ \\
NNM + & & & & \\
$\quad \begin{array}{l}P-E \text { experiments } \\
\text { NNM + iteration }\end{array}$ & $944 \pm 542$ & $\mathrm{~ns}$ & $5.52 \pm 3.13$ & $\mathrm{~ns}$ \\
\hline
\end{tabular}

sensed chl a concentration over the 2 wk period (Fig. 6a). Class I pixels were identified as those with a probability of diatom occurrence $>25 \%$ and a stable or increasing chl a concentration. Class II pixels were those with a probability of diatom occurrence $>25 \%$ and a decreasing chl a concentration (chl a concentration in the second week was $<75 \%$ of chl a concentration in the first week of the study period), and Class III pixels were identified as those where the probability of diatoms occurrence was $\leq 25 \%$. Partitioning the data into 2 separate weeks to assess the derivative in chl a concentration resulted in an increase in pixels with no data due to cloud cover. Water-column production was computed with the NNM for Class I and Class III pixels and using either the measured parameters (Fig. 6b) or the parameters retrieved from the iterative approach for Class II pixels (Fig. 6c). Partitioning of the study area returned a production map that is not as smooth as those generated previously. However, when averaged over the study area, the magnitude of water-column production normalised to the water-column chl a $(\Lambda)$ compared well with the measurements from the in situ incubations (Table 3).

\section{DISCUSSION}

Primary production can be calculated using many different approaches, and ultimately can be applied to satellite images of ocean colour to obtain synoptic fields of global oceanic production (Longhurst et al. 1995, Antoine et al. 1996, Behrenfeld \& Falkowski 1997). However, to compute primary production, photosynthetic parameters must be assigned. Assign- ment of photosynthetic parameters may be made using either continuous or step-wise approaches (Platt \& Sathyendranath 1999). As pointed out by Longhurst (1998), the ocean can be divided into a suite of biogeochemical provinces, each with its own specific physical and biogeochemical properties. These provinces may each be assigned sets of photosynthetic parameters specific for each season, as in the first estimate of global marine primary production by remote sensing (Longhurst et al. 1995). Obviously, this will introduce some discontinuities at the boundaries of the provinces. This problem has been addressed in the NNM (Platt et al. in press). This approach has the advantage of providing values of photosynthetic parameters on a pixel-by-pixel basis and is used on archived data for the areas studied. In other cases (Antoine et al. 1996, Behrenfeld \& Falkowski 1997), assignment of photosynthetic parameters has been performed with temperaturedependent models. Although the use of temperature as a proxy for phytoplankton metabolism has the advantage of providing a means to assign photosynthetic parameters on a pixel-by pixel basis, there are arguments against the approach. For some biogeochemical provinces, using temperature to capture the variability in phytoplankton metabolism can be inappropriate, as shown by Bouman et al. (2005) for the Arabian Sea, where $P_{m}^{B}$ was related only weakly to temperature. In the laboratory, an increase in cell metabolism with an increase in temperature is expected (Eppley 1972). However, in the ocean, an increase in temperature is often (but not always) associated with increased stratification of the water column, which limits the access to nutrients. These contrasting effects of temperature that may or may not occur in different regions of the globe are a strong limitation to modelling phytoplankton metabolism as a function of temperature (Behrenfeld et al. 2002). A second disadvantage with using temperature as a proxy for photosynthetic parameters is that, as for the NNM, there should be comprehensive information available describing variability in metabolic data, and this could be a major problem in some parts of the globe, especially in the southern hemisphere, where data on photosynthetic parameters are scarce, or even non-existent. Here, we explore some of the possible approaches for assigning photosynthetic parameters to estimate primary production from remote sensing of ocean colour. 


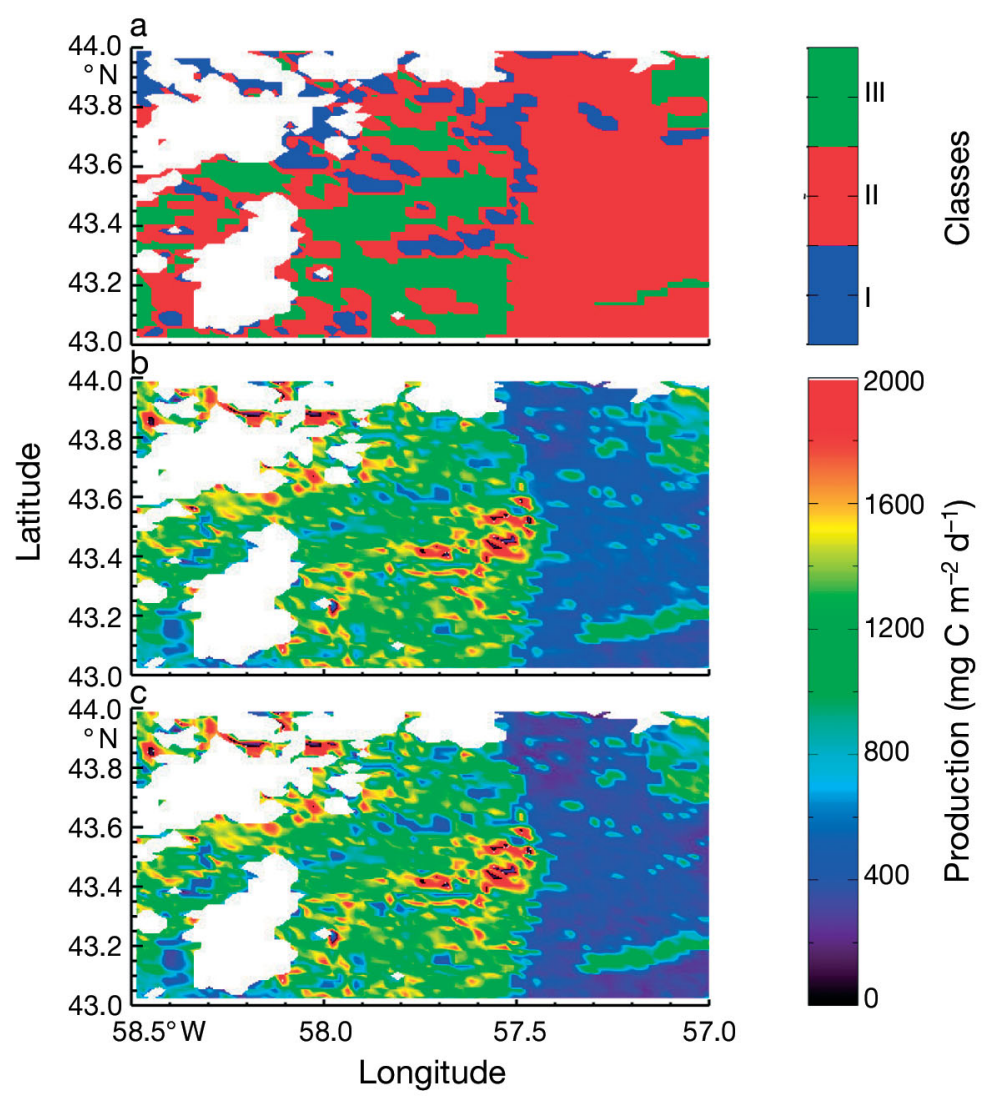

Fig. 6. (a) Classification of pixels according to physiological state and community composition of the phytoplankton. Class I (blue) represents diatom bloom conditions, Class II (red) represents diatom declining conditions and Class III (green) represents mixed community conditions; (b) water-column primary production ( $\mathrm{mg} \mathrm{C} \mathrm{m} \mathrm{C}^{-2} \mathrm{~d}^{-1}$ ) calculated using the nearest-neighbour method (NNM) for pixels identified as Classes I and III and using average photosynthesisirradiance parameters for pixels identified as Class II; (c) water-column primary production ( $\mathrm{mg} \mathrm{C} \mathrm{m}^{-2} \mathrm{~d}^{-1}$ ) calculated using the NNM for pixels identified as Classes I and III and using the photosynthetic parameters retrieved by the iterative approach for pixels identified as Class II

The Lagrangian study in the Northwest Atlantic shelf captured a dynamic phytoplankton community. Sampling took place at the end of a major spring bloom (Fig. 3), so the productivity (as represented by $\Lambda$ and photosynthetic parameters) was not constant, but rather decreased over the nutrient-limited tail end of the bloom (Pommier et al. 2008). This decrease in productivity has already been observed in the decline of other blooms (Platt et al. 1992). The physiological state of the phytoplankton communities evolve with time, and in our study the species composition changed in time and space, being diatom-dominated during the Lagrangian Study and small-cell dominated on D8 and D20 (Figs. 2c \& 4C; see also Pommier et al. 2008). Three classes of phytoplankton populations were designated: Class I represented the diatom bloom; Class II represented the declining diatom phase; and Class III represented a community of small-cell phyto- plankton. The species composition has been observed microscopically (Pommier et al. 2008), by pigment analysis (Fig. 4c) and by satellite imagery (Fig. 2c). It is important to realise that this aquatic system was temporally dynamic and spatially variable. The seasonal progression proceeded at different rates and in different phases (I to III) at different points within the study area. The composite images captured the spatial variation whereas the temporal variability was averaged over a 2 wk period. However, biomass was highly variable in the study area over this time period, which required a comparison of the chl a-normalised production $\Lambda$ between in situ and satellitederived production (Table 3 ).

\section{Iterative approach}

The iterative approach is not a method for assignment of photosynthetic parameters but rather a method to retrieve photosynthetic parameters from in situ incubations (Forget et al. 2007). We used this approach to validate the retrieval of photosynthetic parameters, noting that parameters so retrieved could eventually be added to a database for enhancing the NNM or a temperature-dependent models. In this study, the iterative approach could be applied only to stations identified as Class II (the declining bloom phase) for which the number of in situ observations was sufficient. Thus the estimates of the parameters are representative of this Class only and should not be considered representative of the other Classes, where the iterative approach strongly underestimates production compared with in situ measurements (Tables 2 \& 3). However, when applied to Class II production (Table 2), the estimates compared well with results of both in situ measurements and computations from measured photosynthetic parameters.

\section{Temperature-dependent model}

$P_{m}^{B}$ is related to temperature (Platt et al. 2005, Bouman et al. 2005) and $\alpha^{B}$ is affected mainly by light history (Platt \& Jassby 1976). For entire ecosystem studies, temperature is an appropriate physical factor 
to incorporate into estimations of productivity, but light history is more complex to interpret. Because we were not studying discrete water samples from specific depths, but rather the entire water column over a wide range of incident irradiances, light history cannot be treated in the same way as other physical factors such as temperature. As reported by Platt \& Jassby (1976) and Behrenfeld et al. (2004), the 2 photosynthetic parameters are correlated in many aquatic systems. Thus, temperature probably could be a good indicator of $\alpha^{B}$ in large scale studies (Fig. 1a). As temperature increases, there is a change in community composition from larger cells in nutrient-rich cold waters to smaller cells in stratified warm waters. The photosynthetic parameter $\alpha^{B}$ is inversely dependent on light absorption. It is widely accepted that decreasing phytoplankton cell size reduces the packaging effect, which returns higher specific absorption. Thus, if quantum yield were constant within phytoplankton groups, we would expect an increase in $\alpha^{B}$ as phytoplankton cell size decreased. As shown by Platt et al. (2005), $\alpha^{B}$ is positively related to the specific absorption $a^{*}$ at $676 \mathrm{~nm}$, which increases with a decrease in cell size, and is negatively correlated with the proportion of micro-phytoplankton in the community. Thus, as the phytoplankton size class changes, both photosynthetic parameters increase with a decrease in cell size (Platt et al. 2005).

On average, we found good agreement between the parameters estimated from the temperature model and parameters measured from the $P-E$ experiments (Table 1). The computed and measured water-column productions compared well for Class II and Class III stations, but underestimated production (in comparison with simulated in situ measurements) for Class I stations. However, for average chl a-normalised production over the study area, the temperature model returned a mean value in good agreement with that of the in situ incubation and with production computed from measured parameters. The relationship developed by Bouman et al. (2005) and Platt et al. (2005) performed well for observations from the Northwest Atlantic. However, as stressed by Behrenfeld et al. (2002) and Bouman et al. (2005), temperature-dependent models for photosynthetic capacity should be used with caution, and only in areas where the appropriate relationships have been established.

\section{Nearest-neighbour method}

The NNM is not subject to the limitations of the temperature model and thus is applicable to all regions where a data compilation of photosynthetic parameters, temperature and chl a concentration is available
(Platt \& Sathyendranath 2002, Platt et al. in press). The database used for this study covered the North Atlantic and included about 1500 entries. However, photosynthetic parameter data are scarce in certain parts of the globe (Longhurst et al. 1995). More photosynthesisirradiance experiments should be performed in these regions to enhance the global database. Another option for augmenting the global database is use of in situ production experiments to retrieve photosynthetic parameters (Forget et al. 2007) since many in situ production data are available globally (for example, from JGOFS studies).

The NNM provided good estimates of water-column production for mixed-population conditions (Class III) and in diatom bloom conditions (Class I). However, for the declining phase of the diatom bloom (Class II), water-column production was strongly overestimated (Table 2). As noted previously, the declining phase of a phytoplankton bloom has lower photosynthetic capacity than the bloom phase (Platt et al. 1992). The database represents the general trend in the physiological state of the phytoplankton community. The declining phase of the spring diatom population lasted for a period of only $2 \mathrm{wk}$ over the course of the year (Fig. 3). Thus, the database is not suitable for this specific condition, which is short-lived. Dividing the database of photosynthetic parameters according to the physiological status of the phytoplankton community and according to the community composition would solve this problem. Use of a diatom-identification algorithm (Sathyendranath et al. 2004) supplemented by a temporal derivative of chl a concentration provides a tool to map the different phases of the diatom bloom (blooming versus declining) and the mixed phytoplankton community (Fig. 6). From this analysis, we found a substantial number of pixels classified as in declining diatom conditions (Class II, red pixels in Fig. 6a). Averaging the estimates of primary production using a combination of the NNM for blooming (Class I) and mixed community (Class III) conditions, and either the measured photosynthetic parameters (Fig. 6b) or the parameters retrieved from the iterative approach (Fig. 6c) provided estimates falling within the SD of the in situ measurements (Table 3).

\section{Remote-sensing applications}

Over the past decade, there has been an increased interest in the partition of marine microflora into phytoplankton functional types (PFTs) for modelling the carbon cycle (Le Quéré et al. 2005). Each PFT has a potentially different photosynthetic response to available light. They are also subject to changes in pigment composition and packaging effect, which 
results in variation in their optical properties (Nair 2007). These optical properties can be tracked by remote sensing of ocean colour using algorithms tuned to identify particular PFTs such as diatoms (Sathyendranath et al. 2004), Trichodesmium (Subramaniam et al. 1999) and other phytoplankton groups (Alvain et al. 2005). Using such algorithms with the time derivative of the chl a concentration, the global ocean could be partitioned according to the dominant PFT and according to the occurrence of bloom or declining-bloom conditions. Provided that a database of photosynthetic parameters were available for each of these conditions and for the various PFTs, modelling of global primary production could be approached by using the NNM (Platt et al. in press) to assign the photosynthetic and chl a profile parameters. The future would seem to lie in the development of intelligent (conditional branching) algorithms for this purpose, along the lines of the first steps described here.

Acknowledgements. M.H.F. was supported by a NSERC grant to T.P. This work was also supported by the Canadian Surface Ocean-Low Atmosphere Study (C-SOLAS) and by the Canadian Space Agency through its Government Related Initiative Programme (GRIP). We thank J. Anning for collection and processing of the photosynthesis-light experimental data in the Northwest Atlantic. We also thank G. White III and C. Caverhill for assistance in processing satellite imagery and 3 anonymous referees for useful comments on the manuscript.

\section{LITERATURE CITED}

Alvain S, Moulin C, Dandonneau Y, Bréon FM (2005) Remote sensing of phytoplankton groups in Case 1 waters from global SeaWiFS imagery. Deep-Sea Res I 52: 1989-2004

Antoine D, André JM, Morel A (1996) Oceanic primary production 2. Estimation at global scale from satellite (Coastal Zone Color Scanner) chlorophyll. Global Biogeochem Cycles 10:57-69

Behrenfeld MJ, Falkowski PG (1997) Photosynthetic rates derived from satellite-based chlorophyll concentration. Limnol Oceangr 42:1-20

Behrenfeld MJ, Randerson JT, McClain CR, Feldman GC and others (2001) Biospheric primary production during ENSO transition. Science 291:2594-2597

Behrenfeld MJ, Marañó E, Siegel DA, Hooker SB (2002) Photoacclimation and nutrient-based model of light-saturated photosynthesis for quantifying oceanic primary production. Mar Ecol Prog Ser 228:103-117

Behrenfeld MJ, Prasil O, Babin M, Bruyant F (2004) In search of a physiological basis for covariations in light-limited and light-saturated photosynthesis. J Phycol 40:4-25

Bird RE (1984) A simple, solar spectral model for directnormal and diffuse horizontal irradiance. Sol Energy 32: 461-471

Bouman HA, Platt T, Sathyendranath S, Stuart V (2005) Dependance of light-saturated photosynthesis on temperature and community structure. Deep-Sea Res I 52: 1284-1299
Eppley R (1972) Temperature and phytoplankton growth in the sea. Fish Bull 70:1063-1084

Forget MH, Sathyendranath S, Platt T, Pommier J, Vis C, Kyewalyanga MS, Hudon C (2007) Extraction of photosynthesis-irradiance parameters from phytoplankton production data: demonstration in various aquatic systems. J Plankton Res 29:249-262.

Irwin B, Anning J, Caverhill C, Platt T (1990) Primary production on the Labrador Shelf and in the Strait of Belle Isle in May 1988. Can Data Rep Fish Aquat Sci 784:1- 96

Le Quéré C, Harrison SP, Prentice IC, Buitenhuis ET and others (2005) Ecosystem dynamics based on plankton functional types for global ocean biogeochemistry models. Global Change Biol 11:2016-2040

Longhurst A (1998) Ecological geography of the sea. Academic press, London.

Longhurst A, Harrison G (1989) The biological pump: profiles of plankton production and consumption in the upper ocean. Prog Oceanogr 22:47-123

Longhurst A, Sathyendranath S, Platt T, Caverhill C (1995) An estimate of global primary production in the ocean from satellite radiometer data. J Plankton Res 17: 1245-1271

Malin G, Turner SM, Liss PS (1992) Sulfur: the plankton/climate connection. J Phycol 28:590-597

Morel A, Berthon JF (1989) Surface pigments, algal biomass profiles, and potential production of the euphotic layer: relationships reinvestigated in view of remote-sensing applications. Limnol Oceanogr 34:1545-1562

Nair A (2007) Bio-optical properties of some phytoplankton functional types. PhD thesis, Dalhousie University, Halifax, Nova Scotia

Platt T, Jassby AD (1976) The relationship between photosynthesis and light for natural assemblages of coastal marine phytoplankton. J Phycol 12:421-430

Platt T, Sathyendranath S (1988) Oceanic primary production: estimation by remote sensing at local and regional scale. Science 241:1613-1620

Platt T, Sathyendranath S (1993) Estimators of primary production for interpretation of remotely sensed data on ocean color. J Geophys Res C 98:14 561-14 576

Platt T, Sathyendranath S (1999) Spatial structure of pelagic ecosystem processes in the global ocean. Ecosystems 2: 384-394

Platt T, Sathyendranath S (2002) Modelling primary production - 30. Aquabiology 141:341-345 (in Japanese)

Platt T, Gallegos CL, Harrison WG (1980) Photoinhibition of photosynthesis in natural assemblage of marine phytoplankton. J Mar Res 38:687-701

Platt T, Sathyendranath S, Caverhill CM, Lewis MR (1988) Ocean primary production and available light: further algorithms for remote sensing. Deep-Sea Res I 35: 855-879

Platt T, Sathyendranath S, Ulloa O, Harrison WG, Hoepffner N, Goes J (1992) Nutrient control of phytoplankton photosynthesis in the Western North Atlantic. Nature 356: $229-231$

Platt T, Bouman H, Devred E, Fuentes-Yaco C, Sathyendranath S (2005) Physical forcing and plankton distributions. Sci Mar 69:55-73

Platt T, Sathyendranath S, Forget MH, White GN, Caverhill C, Bouman H, Devred E, Son SH (in press) Operational estimation of primary production at large geographical scales. Remote Sens Environ

Pommier J, Michel C, Grosselin M (2008) Particulate organic carbon export in the upper twilight zone during the decline of the spring bloom. Mar Ecol Prog Ser (in press) 
Sathyendranath S, Platt T (1993) Remote sensing of water-column primary production. In: Li WKW, Maestrini SY (eds) Measurement of primary production from the molecular to the global scale. ICES, Copenhagen, p 236-243

Sathyendranath S, Platt T, Caverhill CM, Warnock RE, Lewis MR (1989) Remote sensing of oceanic primary production: computations using a spectral model. Deep-Sea Res I 36: 431-453

Sathyendranath S, Longhurst A, Caverhill CM, Platt T (1995) Regionally and seasonally differentiated primary production in the North Atlantic. Deep-Sea Res I 42: 1773-1802

Editorial responsibility: Howard Browman (Associate Editorin-Chief), Storebø, Norway
Sathyendranath S, Cota G, Stuart V, Maass H, Platt T (2001) Remote sensing of phytoplankton pigments: a comparison of empirical and theoretical approaches. Int J Remote Sens 22:249-273

Sathyendranath S, Watts L, Devred E, Platt T, Caverhill C, Maass H (2004) Discrimination of diatoms from other phytoplankton using ocean-colour data. Mar Ecol Prog Ser 272: $59-68$

Subramaniam A, Carpenter EJ, Falkowski PG (1999) Biooptical properties of the marine diazotrophic cyanobacteria Trichodesmium spp. II. A reflectance model for remote sensing. Limnol Oceanogr 44:618-627

Submitted: January 30, 2007; Accepted: June 30, 2007 Proofs received from author(s): November 29, 2007 